\title{
physics
poday
}

\section{Volcanoes of the Solar System and Planetary Volcanism: A Study of Volcanic Activity in the Solar System}

Charles Frankel, Peter Cattermole, and Don L. Anderson

Citation: Phys. Today 50(3), 77 (1997); doi: 10.1063/1.881696

View online: http://dx.doi.org/10.1063/1.881696

View Table of Contents: http://www.physicstoday.org/resource/1/PHTOAD/v50/i3

Published by the American Institute of Physics.

\section{Additional resources for Physics Today}

Homepage: http://www.physicstoday.org/

Information: http://www.physicstoday.org/about_us

Daily Edition: http://www.physicstoday.org/daily_edition

\section{ADVERTISEMENT}

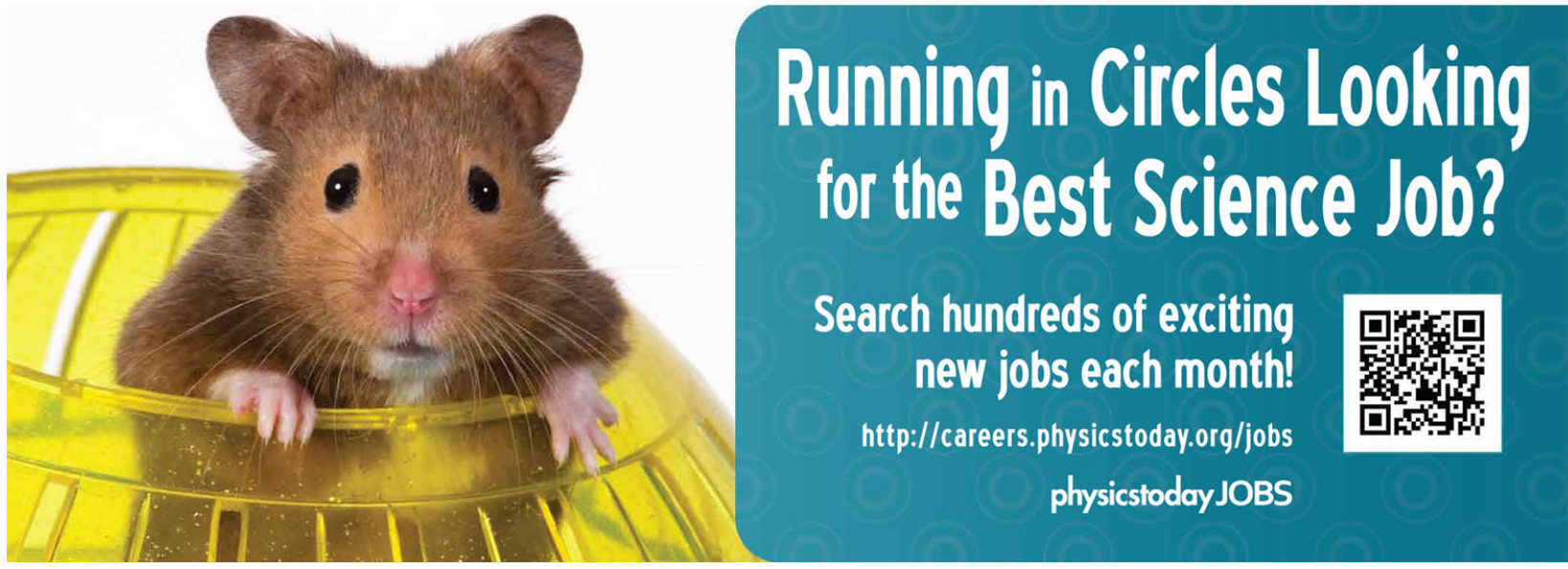




\section{Planetary Volcanology: A Field Ripe for Exploitation by Physicists}

\section{Volcanoes of the Solar System}

Charles Frankel

Cambridge U. P., New York, 1996.

232 pp. $\$ 70.00 h c(\$ 24.95 p b)$

ISBN 0-521-47201-6 hc

(0-521-47770-0 pb)

\section{Planetary Volcanism: A Study of Volcanic Activity in the Solar System}

Peter Cattermole

Wiley, New York, 1996. 2nd

edition. 417 pp. $\$ 98.95 \mathrm{hc}$

ISBN 0-471-96051-9

\section{Reviewed by Don L. Anderson}

Earth scientists are in a bind: They have only one object to study. Most scientists have many objects, be those particles, atoms, molecules, species, stars or galaxies. Not only that, but Earth scientists are presented with a completed experiment and must infer what happened. Many of their hypotheses cannot be tested, and many "well-accepted facts" are simply oft-repeated opinions or assumptions. Models often use up all the data or observations and leave nothing with which to test their predictive power.

Planetary exploration has opened up a new data base and a new source of ideas. The roles of impacts, magma oceans, resurfacing, volatile controlled rheology and polar wander are important concepts that essentially have been brought into geology by observers of other worlds. Regrettably, few Earth scientists are aware of such developments in planetology, and few planetologists apply their skills to Earth.

Comparative planetology is a small but important discipline. Although Charles Frankel's Volcanoes of the Solar System and Peter Cattermole's Planetary Volcanism are about volcanoes, their common theme is comparisons among planets. Volcanoes offer clues to the ways a planet evolves and

DON L. ANDERSON of the California Institute of Technology is interested in the origin and evolution of the terrestrial planets. gets rid of its heat. Every object in the Solar System seems to have its own style, and a modern student of volcanic processes must look up as well as down.

Volcanology has been mainly a descriptive science, and there is a large role for physicists in this business. Although Lord Kelvin was grossly wrong about the age of Earth, he correctly calculated how fast a body would lose its original heat by conduction, and the Kelvin effect may be as important a contributor as radioactive decay. Getting the heat out of a planet by convection, conduction, radiation, melting, fracturing, intrusion, extrusion, uplift, subduction and overturn involves such complex issues and requires such a toolbox of analytical skills that the science is in its infancy.

These books are the place to start for both physicists and geologists. Geologists need the other-world perspective, even if they are professional volcanologists. Physicists need to know the variety of styles available to a planet relieving itself of pent-up heat before they set up their equations and boundary conditions. Presumably, the physics is the same from planet to planet, although the outcomes are quite different.

Frankel's book is primarily for the nonspecialist. It is an easily digestible 232 pages, with just enough illustrative and tabular material to complement the text. It starts with the elements of planetary thermodynamics and covers all types of terrestrial volcanism. It then undertakes a tour of volcanoes in the Solar System, starting with the Moon and Mars. It proceeds to tell us essentially everything that is known about volcanism on Venus as well as Io, Europa and other moons of the outer planets. In its tenth and final chapter, it provides a complete planetary perspective and discusses the reasons various bodies are different. Climates and atmospheres are also discussed. The excellent table of contents, index and reference list make this a valuable and scholarly source book. This book could be used as an introductory text in planetary science as well as geology.

The book by Cattermole is a revision of the 1989 edition, updated to include new knowledge of Venus, outer-planet moons and, to a lesser extent, other Solar System objects. It is twice as long as Frankel's book and contains 140 plates, many in color, and about 25 tables. It is for the serious student and those who wish to become expert on the subject.

As befits its size and cost and its author's interests, the book has more chemistry, petrology and rheology than Frankel's. As does Frankel, Cattermole devotes about 40 pages to each volcanic planet or class of objects (the icy moons), and likewise covers the fundamentals very well.

There are many books about volcanoes. Most of them are about volcanoes only. Even if you have five or six of these books, you will probably want Frankel's. If you don't have any, this should be the first one, because it places volcanoes in context. Nonetheless, planetary scientists and serious volcanologists will have to read Cattermole's book eventually. But if you have a lot of other things to worry about, or you want a book you can enjoy on a three-hour airplane or train ride, then pick up Frankel's. You probably don't need both.

The physics of volcanoes is poorly understood mainly because physicists have not taken an interest in the problem. Volcanic eruptions have not been quantified in the same sense as earthquakes and impacts have. Words such as energy, velocity, nucleation, partitioning, pressure, entropy, thermodynamics, conductivity and the like will not be found in these books. Here is a field ripe for exploitation by physicists. Kelvin may have been burned, but this shouldn't discourage modern physicists from turning their attention back to the fundamental problem about how Earth loses its heat.

\section{Infinite Potential: The Life and Times of David Bohm}

\author{
F. David Peat \\ Addison-Wesley, Reading, Mass., \\ 1996. 368 pp. $\$ 25.00 \mathrm{hc}$ \\ ISBN 0-201-40635-7
}

The dust jacket of Infinite Potential: The Life and Times of David Bohm 